\title{
Difficulties of Multiple-choice Question-Generation Encountered by Elementary Students in Social Studies: A Case Study
}

\author{
Chih-Wei Kuo and Fu-Yun Yu
}

\begin{abstract}
This study, based on a case study research design, aimed to identify Taiwanese elementary students' difficulties in the process of generating multiple-choice items in the subject of social studies. Six sixth grade pupils with different achievement levels were recruited to participate for the entire 2015 school year. Each participant was required to pose two multiple-choice items in $\mathbf{2 0}$ minutes in class after the teacher finished teaching each social studies unit (24 units in total). Data collection methods included participant observations, document analysis of student-generated questions, and individual face-to-face interviews. The qualitative data analysis method was adopted for inducing convergent themes. Four main themes emerged related to the difficulties in student question-generation: finding appropriate content and the main ideas of the study material to construct questions on, completing the specified number of questions with options of adequate quality, formulating linguistically appropriate question stems, and constructing questions that involve higher-order cognitive levels. Based on the findings obtained from this study, explicit pedagogical suggestions regarding supports to help mitigate the difficulties that students encountered during student question-generation are provided, with their applicability to other larger contexts attended to.
\end{abstract}

Index Terms-Experienced difficulties, elementary students, student question-generation, social studies teaching, multiple-choice items.

\section{INTRODUCTION}

Student question-generation (SQG) has been one of the contemporary innovative pedagogies and learning approaches in which it is not the teachers but instead the students who pose questions in a variety of formats based on a given problem, a certain topic, or a specific situation. It serves as a promising teaching strategy to engage students in self-reflection, self-evaluation, and self-adjustment, thereby maximizing the effectiveness of student learning. The existing literature has indicated the potential benefits of incorporating SQG into teaching, and documented various aspects of the positive effects on students [1], [2]. While many studies have evidenced that SQG can promote and facilitate the personal growth of learners, most were conducted with a quantitative experimental approach to examining how effective SQG is in isolation or in combination with different pedagogical designs [3]-[9]. Few

Manuscript received March 20, 2017; revised September 2, 2017.

Chih-Wei Kuo and $\mathrm{Fu}-\mathrm{Yun} \mathrm{Yu}$ are with the Institute of Education, National Cheng Kung University, Tainan, Taiwan (e-mail: louielucky@hotmail.com, fuyun.ncku@gmail.com). studies have been undertaken to examine the learning process and focus on the difficulties that students face when engaging in SQG. The current research, based on a case study on the difficulties of SQG encountered by Taiwanese students, is an effort to extend the existing literature.

\section{LITERATURE REVIEW}

SQG has been widely used for enhancing learning in a variety of disciplines, mostly in mathematics, but also in the natural and life sciences, as well as humanities and social sciences. Given different names in literature, such as student problem posing, student question posing, student problem authoring, student constructed assessment, and student-contributed assessment, SQG is well grounded in information-processing theory, which involves the dynamics of information storage, processing, retrieval, and transfer, and engages individuals in the practices of rehearsal, organization, and elaboration [10]. SQG is also supported by metacognition and constructivism, as it encourages students to transform and structure received information into personally meaningful knowledge through the use of different metacognitive abilities, such as reflection, monitoring, planning, evaluation, and adjustment [10].

SQG occurs under three types of situations: free, semi-structured, and structured [11]. SQG under a free situation enables individuals to engage in creative writing and generate questions in a less constrained way, such as the focal study material. Semi-structured SQG, however, gives the students more boundary conditions, such as unfinished problem structures, a picture, equation, or solving method as a reference point for question generation. Structured SQG occurs within a well-designed context, and individuals make changes based on existing questions to develop new ones. The three types of SQGs serve different purposes and achieve different goals with various pedagogical designs. Since the current study aims to examine the general difficulties that students face with SQG, we adopt the free type of SQG and put students into a naturalistic setting so as to better capture the problems they encounter.

A number of studies have reported that students appear to perceive SQG as challenging [12]-[15]. Yu [15], for instance, found that nearly $60 \%$ of the participating university students regarded SQG as difficult or very difficult. Such difficulties are probably related to students' limited experience of SQG during their formal education [12], [15], [16]. Several strategies have thus been utilized to deal with this, such as the use of story grammar [17], generic question stems [18], and 
the What-if-not strategy [19]. Strategies such as these have proved beneficial and effective for mitigating the difficulties of SQG [15], [20], [21]. Since these difficulties may arise from multiple sources [12], an in-depth investigation may illuminate the causes of these and help to develop corresponding scaffolds and forms of feedback that can aid related pedagogical interventions.

Thus far, only a few studies have attempted to identify the difficulties of SQG based on content analysis and surveys [12], [16], [22]-[24]. The results of content analysis revealed that students, while engaging in SQG, may experience difficulties and generate questions that are implausible, incomplete, lacking in linguistic and mathematical complexity, and overly open-ended [16], [22]-[24]. The survey results further showed that the causes of difficulties in a mathematical SQG activity differ, ranging from the nature of problem posing itself to the characteristics of the students involved, such as a lack of mathematical knowledge or familiarity with SQG [12]. Much of the previous research in this area was conducted in the context of mathematics education, with few discussions in other disciplines. Since there may exist variations in different fields, there is thus a need to expand the existing literature on the difficulty of SQG to other disciplines. Moreover, previous studies on the difficulties of SQG have rarely discussed the issue of individual differences. In a single classroom, there exists a mixed level of students, including low-, middle-, and high-achieving learners. It is believed that the difficulties related to SQG may vary among students with different achievement levels, and thus an empirical study is needed to obtain more evidence. To address these issues, the current study aims to implement SQG in a social studies context, a relatively less studied field, and investigate the underlying difficulties students with different achievement levels encounter. The guiding question is formulated as follows: What difficulties do students in general and at different achievement levels encounter while engaging in SQG in social studies?

\section{METHOD}

This study is conducted using a case study method. The case study, relying heavily on a variety of data from multiple sources, makes it possible not only to delve into a phenomenon in great depth, but also to provide a complete context giving a rich description of events [25]. The adoption of a case study approach in the present work can offer an in-depth and thorough understanding of the underlying difficulties students encounter while they engage in SQG.

\section{A. Research Site and Participants}

The study took place for the entire 2015 school year, and was situated in a rural small-scale primary school in Tainan City, Taiwan, in which a total of 25 school pupils enrolled. The researchers recruited all pupils enrolled in Grade $6(n=6)$, aged 11-12 years, to participate. Among the six participants, four were boys and two were girls. The participants, based on their overall academic achievement in the previous school year, fell into three categories: high-, average-, and low-achievers. Table 1 shows the basic information of the six participants, with pseudonyms used to avoid revealing their true identities.

TABLE I: THE BASIC INFORMATION OF THE SIX PARTICIPANTS

\begin{tabular}{cccc}
\hline $\begin{array}{c}\text { Participants } \\
\text { (pseudonym) }\end{array}$ & Academic achievement level & Label & Gender \\
\hline Ta-han & high & H1 & boy \\
Mei-ling & high & H2 & girl \\
Cheng-hao & average & A1 & boy \\
Hsiao-hsin & average & A2 & boy \\
Te-wei & low & L1 & boy \\
Hsiao-chun & low & L2 & girl \\
\hline
\end{tabular}

\section{B. Research Procedures and Data Collection Methods}

The study incorporated SQG into a social studies classroom, beginning in September of 2015 and ending in June of 2016. Data collection methods included participant observations, document analysis of student-generated questions, and individual face-to-face interviews. The study, following the procedures outlined below, consisted of three phases:

1) The pre-SQG phase: This was the orientation phase. The teacher gave a brief overview of the SQG activity and described the purpose of incorporating SQG in the class. The multiple-choice question type was adopted in the activity, since it offers great possibilities for assessing a wide range of cognitive levels [26].

2) The SQG phase: This was the implementation phase. After the teacher finished teaching each social studies unit (24 units in total), each participant was directed to produce two multiple-choice items on the current week's content in 20 minutes in class. If the work could not be completed within the given time, the participants were asked to take it home to finish and turn it in the next class. Each multiple-choice question that participants generated needed a question-stem, four options, an answer key, and the source. In the process of SQG, the researchers conducted classroom observations, took field notes of special events, and documented the struggles that students were facing. The researchers also collected the SQG writing products to analyze the underlying difficulties the students encountered.

3) The post-SQG phase: This was the interview phase. After the last SQG activity, an individual face-to-face interview with each student was arranged. The interviews occurred in an unoccupied classroom, each lasting 15 to 25 minutes. The interview consisted of questions that enabled students to reflect on the experience of SQG and express their opinions and tackling tactics, including what difficulties they encountered in SQG, how they went about SQG (i.e., determining what and how to generate questions), how they coped with the difficulties encountered during the activities, and so on. All interviews were audio-recorded and transcribed for further analysis.

\section{Data Analysis}

The researchers analyzed the data, following the qualitative data analysis model proposed by Miles and Huberman - data reduction, data display, and conclusion verification [27]. The three types of data collected during the 
study were examined for convergence to form themes. Figure1 shows the research flow of the present study.

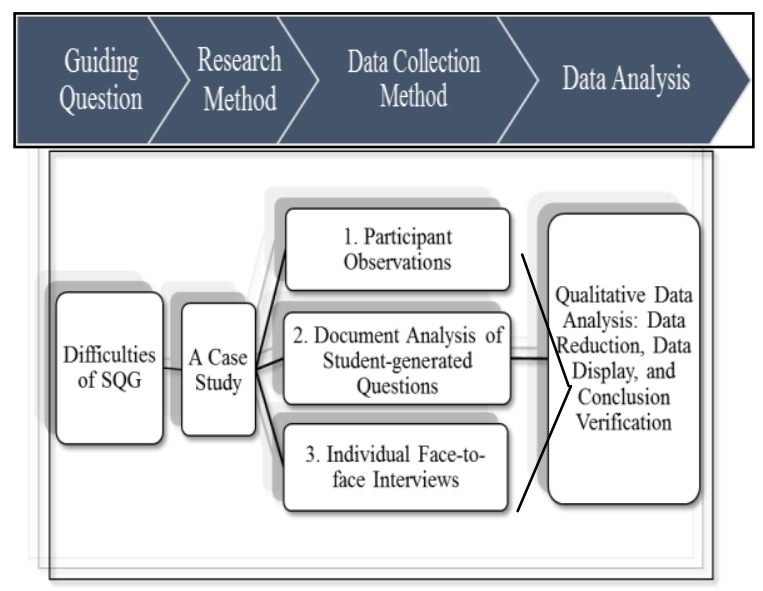

Fig. 1. The research flow of the present study.

\section{FINDINGS}

With regard to the difficulties encountered in the process of SQG, based on the triangulation of classroom observation data, interview data, and SQG writing products (a total of 288 questions based on 24 social science units from the six participating students), four main themes emerged, and these will be discussed separately, as follows.

\section{A. Difficulties in Finding Appropriate Content and the} Main Ideas of the Study Material to Construct Questions on

After teaching the first unit at the very beginning of the fall semester, the teacher led the whole class to carry out the SQG activity. Although the teacher reminded students of the key points of the focal unit, in general the low- and average-achieving students could not find any suitable content in the study material to construct questions on, as shown in example 1.

\begin{tabular}{|c|c|}
\hline \multicolumn{2}{|l|}{ Example 1: } \\
\hline Teacher: & $\begin{array}{l}\text { Now I gave you all } 20 \text { minutes to come up with two } \\
\text { multiple-choice questions based on the content we } \\
\text { learned in the first unit. The question must contain a } \\
\text { question stem, four alternatives, an answer key, and the } \\
\text { source page of the question. }\end{array}$ \\
\hline $\begin{array}{l}\text { Hsiao-hsin } \\
\text { (A2): }\end{array}$ & $\begin{array}{l}\text { (Immediately raising his hand) But I did not know what } \\
\text { question I should pose. }\end{array}$ \\
\hline Teacher: & $\begin{array}{l}\text { Earlier I lead the whole class to highlight the main ideas } \\
\text { in the unit. You could have found inspiration from those } \\
\text { highlighted parts. }\end{array}$ \\
\hline $\begin{array}{l}\text { Hsiao-hsin } \\
\text { (A2): }\end{array}$ & $\begin{array}{l}\text { (Taking a nearby classmate's book to see what is } \\
\text { highlighted) }\end{array}$ \\
\hline & $\begin{array}{l}\text { (Eight minutes later, the teacher circulated around the } \\
\text { classroom, inspecting students' work) }\end{array}$ \\
\hline Teacher: & $\begin{array}{l}\text { Te-wei (L1), why did you leave your SQG workbook } \\
\text { blank? No ideas? }\end{array}$ \\
\hline $\begin{array}{l}\text { Te-wei } \\
\text { (L1): }\end{array}$ & (Nodding) \\
\hline Teacher: & $\begin{array}{l}\text { You can examine the headings in that unit, and then use } \\
\text { those to find inspiration for the questions. }\end{array}$ \\
\hline $\begin{array}{l}\text { Te-wei } \\
\text { (L1): }\end{array}$ & (Nodding once again) \\
\hline
\end{tabular}

The SQG activity was conducted routinely and continued till the end of the spring semester. At the end of the last SQG activity, the teacher interviewed all six participating students individually. Despite nearly a whole school year of SQG practice, three of the four low- and average-achievers stated that the greatest difficulty they encountered was their inability of finding the key points and coming up with questions. As Hsiao-hsin (A2) said, "The questions were hard to come up with... If I got stuck in generating questions, I would ask my classmates directly" (interview). Similarly, Hsiao-chun (L2) stated, "Constructing a question really took me a long time... Several times after I finished reading the assigned pages of the study material, I spent lots of time thinking what questions I should pose (interview)." Hsiao-chun's struggle with finding the appropriate content in the study material was further seen during class observation. Once, while walking around the classroom, the teacher noticed that Hsiao-chun was thinking deeply about her question construction. "During a long period of ten minutes, Hsiao-chun was found to sometimes focus on reading the main text of the study material, sometimes gaze fully at the headings of different sections of the study material, and sometimes look preoccupied with the pictures beside the texts. After ten minutes passed, Hsiao-chun still could not generate her own question (classroom observation)." It seems that the coverage of the study material is too broad for Hsiao-chun to determine the direction and construct her desired question.

In the process of SQG, it was found that high-achieving learners generally used less than two-thirds or even half of the allocated time to complete the assigned task, whereas low-achieving learners took longer, and often still could not complete the task in time. "Within the 20 minutes, on more than one-fourth of the occasions, the low-achievers completed only one question, and sometimes even this could not be done (classroom observation)." Overall, of the 24 in-class SQG activities, it was found that all the students successfully generated two questions in class as expected, except for the two low-achievers. Te-wei (L1), as a slow learner across all subject matters, failed to complete the SOG task nine times $(37.5 \%)$, including generating only one question seven times and not a single question two times. Hsiao-chun (L2), the other low-achiever, who is not adept in language-based subjects, including Chinese and social studies, could not successfully complete her SQG task eight times $(33.33 \%)$, with the submission of one question seven times and no questions once. Though both Te-wei and Hsiao-chun completed their unfinished SQG tasks afterwards, the additional time needed and failure to complete the in-class SQG tasks showed that these two low-achievers faced difficulties with regard to finding appropriate content for the SQG activity.

This finding that the average- and low-achievers could not find appropriate content in the study material to generate questions was further verified by their SQG writing products. For instance, rather than focusing on the main points of the study material (see Examples 2 and 3), the low- and average-achieving students tended to construct questions around insignificant details and trivial numbers appearing in the text (e.g., the death toll of a typhoon in Example 2; the percentage of illiterate women in Example 3). After comparing all of the SQG writing products from the low-, average-, and high-achieving learners, the researchers found 
that such questions did not appear in any of the products of the high-achievers, but only in those of average- and low-achievers, and at a substantial percentage (11.5\%).

\begin{tabular}{|l|}
\hline Example 2: \\
\hline (3) In 2009, how many people died after Typhoon Morakot hit Taiwan? \\
(1) 700 (2) 10,000 (3) 600 (4) 7,500 \\
\hline SQG, Cheng-hao (A1) \\
\hline
\end{tabular}

\begin{tabular}{|l|}
\hline Example 3: \\
\hline (3) What proportion of the world's illiterate adults are women? \\
(1) one-half (2) one-third (3) two-thirds (4) three-quarters \\
\hline SQG, Hsiao-chun (L2) \\
\hline
\end{tabular}

In summary, with regard to theme 1 , the low- and average-achievers had problems finding the important content, suffered from there being too much content covering too wide an area, or focused on inappropriate content in the study materials when constructing questions, as diagrammed in Fig. 2.

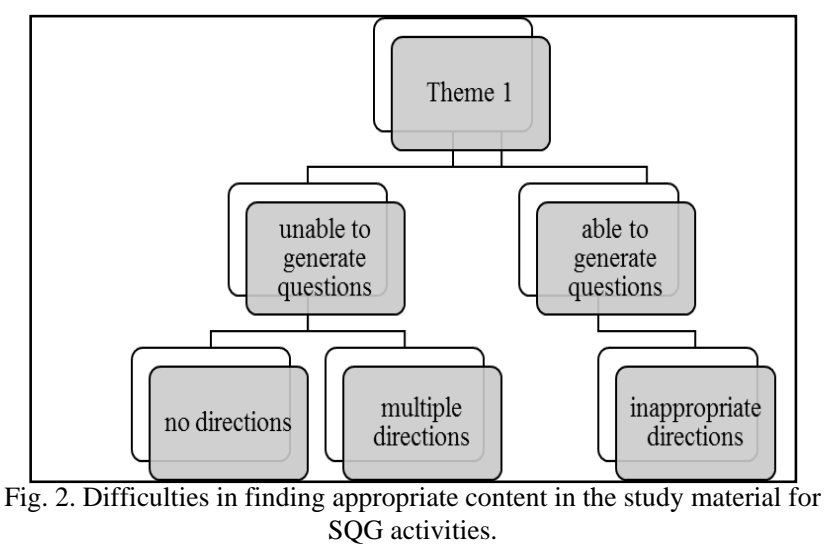

\section{B. Difficulties in Completing the Specified Number of Questions with Options of Adequate Quality}

Students were required to complete two multiple-choice questions for each unit in class; however, as revealed from the interview data, due to differences in unit content, it was difficult for them to generate the specified number of questions with options. As Ta-han (H1) said, "since some units contained a small number of pages, I sometimes barely generated one question in those units, though I finally struggled to come up with another ... I suggest that the specified number of questions could be flexibly adjusted according to the number of pages in the units, rather than a fixed number of questions for all units" (interview). On the other hand, regarding the design of options, the students concurred that the design of four good options was rather difficult. An important criterion in devising good multiple-choice options is the development of plausible distractors [28]. In other words, each question option must be closely related to the stem and have reasonable plausibility, which can be correctly answered by those with a higher level of knowledge, and incorrectly answered by those with a relatively low level of knowledge. Nevertheless, it was found that students in general, even high-achievers, fail to construct good distractors. Example 4, for instance, constructed by Mei-ling (H2) consists of four options in which all are appropriately designed, except for option 3, which is illogical and against common sense. Example 5, generated by
Hsiao-hsin (A2), includes low-quality options (options 2, 3, 4 ), which tend to lack homogeneity in terms of both content and structure. Writing plausible distractors is therefore another difficulty the students confronted in SQG.

\begin{tabular}{|l|}
\hline Example 4: \\
\hline (3) Which of the following is not a good way of financial \\
management? \\
(1) depositing in a bank (2) buying stocks (3) burning money (4) \\
buying an insurance policy \\
\hline SQG, Mei-ling (H2) \\
\hline
\end{tabular}

\begin{tabular}{|l|}
\hline Example 5: \\
\hline (1) What is the purpose of currency use? \\
(1) a tool for trading (2) playing marbles (3) throwing into the \\
ditch (4) it can be eaten \\
\hline SQG, Hsiao-hsin (A2) \\
\hline
\end{tabular}

Furthermore, while neither of the options of 'all of the above' and 'none of the above' are recommended by testing specialists [28], [29], but these were present in the SQG of all learners, and especially prevalent in the SQG of the low- and average-achievers. Specifically, of all the options in the 48 questions generated by each participant (i.e., a total of 192 options), $32.3 \%$ of the options were all/none of the above for low- and average-achievers, in stark contrast with the relatively low percentage of $16.7 \%$ for the high-achievers. The high-frequency using all/none of the above by the lowand middle-achievers may indicate the difficulties students encountered in comping up with question options. This also revealed that those students, though able to find content for their SQG, had problems in constructing options of adequate quality.

To sum up, in combination with the difficulties identified earlier, the difficulties of SQG found for theme 2 showed that the students, and particularly the low- and average-achievers, faced considerable challenges in completing the specified number of questions with options of adequate quality.

\section{Difficulties in Formulating Linguistically Appropriate Question Stems}

A question stem can be formulated using either a question form or an incomplete statement form [28], [29]. It has been argued that constructing the question form is easier than the incomplete statement form, and thus novice test makers are suggested to begin posing questions using the former [29]. Nevertheless, several students in the present study stated during the interviews that they experienced considerable difficulties in formulating linguistically appropriate question stems. As Ta-han (H1) mentioned, "In most cases I probably knew the content of my SQG, but I did not exactly know how to formulate the question stem" (interview). Similarly, Mei-ling (H2) said that "Writing the question stem was even more difficult than constructing the options. Although I was able to figure out the content of SQG, I did not know how to express it linguistically" (interview).

The content analysis of the SQG data offers concrete evidence of students' difficulties in formulating the question stems. Two common problems dealing with the construction of question stems are "an extensive use of colloquial expressions" and "an awkward expression of the question form." Other minor linguistic problems include inaccurate, 
incomplete, and lengthy expressions. Overall, although $90.6 \%$ of the question stems formulated by the high-achievers were judged to meet the standard of being linguistically appropriate, only $76.5 \%$ of the question stems formulated by low- and average-achievers were gauged to be linguistically appropriate. These results suggest that formulating question stems using clear language was not yet mastered by the participants, and especially not by the lowand average-achievers.

To conclude, the difficulties of SQG related to theme 3 showed that the low- and average-achievers experienced more difficulties in formulating linguistically appropriate question stems than the high-achievers.

\section{Difficulties in Constructing Questions That Involves Higher-Order Cognitive Levels}

The fourth difficulty for SQG is that the students were generally not able to construct questions which involved higher-order cognitive levels. As such, the questions the students posed were mostly related to the level of 'knowledge' based on Bloom's cognitive taxonomy [30]. This phenomenon was especially obvious in the SQG produced by average- and low-achieving learners (see Examples 6 and 7).

\section{Example 6:}

(1) What religion has a taboo on eating beef?

(1) Hinduism (2) Christianity (3) Buddhism (4) Taoism

SQG, Te-wei (L1)

\section{Example 7:}

(1) Which of the following is not a member of the European Union? (1) United Kingdom (2) France (3) Germany (4) Netherlands

SQG, Hsiao-hsin (A2)

A total of $68.8 \%$ of SQGs by low-achievers and $58.3 \%$ by average-achievers were found to fall into the memory type, with much fewer of these questions $(38.4 \%)$ being produced by the high-achieving learners. The high proportion of SQGs of the memory type that were composed by the average- and low-achievers reflects their relatively superficial processing of the study material during SQG.

Compared with the dominant use of the memory type of SQG by average- and low-achievers, the high-achievers generated a higher percentage of questions that involved comprehension, application or even other higher cognitive levels, which were rarely present in the SQG of the other learners. Examples 8 and 9 present two instances, with the former showing the cognitive levels of comprehension and application, and the latter dealing with the analysis and synthesis levels. In essence, constructing such questions requires the author to comprehend, organize, as well as integrate different concepts and knowledge from a wide range of sources, rather than using the textbook as a single source.

Example 8:
(4) People's lives are affected by the use of nuclear energy. The
following four statements were made by students. Which one
is correct?
(1) "Nuclear energy is very safe and does not pose a threat to our
lives," Hsiao-chin said.

(2) "Nuclear power is green energy," A-ming said.

(3) "Nuclear energy cannot be made into weapons," Hsiao-tao said

(4) "Nuclear energy produces radiation, which may endanger our health and homes," Hsiao-chia said.

SQG, Mei-ling (H2)

Example 9:
(4) Which one of the following is correctly matched regarding the types
$\quad$ and functions of the architecture?
(1) Cave house: prevents temperature loss
(2) Conical tent: facilitates snow sliding off the tent
(3) Ice house: facilitates nomadic migration
(4) Arcade: enables taking shelter from the rain
SQG, Ta-han (H1)

Most of the middle- and low-achievers' SQG were mainly fact- and memory-based, involving less higher-level thinking. The researchers proceeded to inquire into the reasons why those students seldom constructed higher-level thinking questions. The interview results showed three main causes: 1 . The alternatives in the higher-level thinking questions were difficult to devise, compared with lower-level questions. "The alternatives in those (higher-level thinking) questions are very long and quite hard to construct. But if it is the original type (memory-type), as long as I located the specific noun phrases, then hollowed them out into options and came up with other similar options, I could complete it immediately. This way is fast," as noted by Hsiao-hsin (A2) (interview). 2. The higher-level thinking questions involve knowledge integration, and the design of such questions is more challenging. As Hsiao-chun (L2) said, "I think it's hard to come up with several different alternatives at the same time. The alternatives I generated previously (memory-type) were similar. But the alternatives of the new type (higher-level thinking questions) are different, which is a bit complicated for me" (interview). 3. Poor reading ability also affected the production of higher-level thinking questions. As Te-wei (L1) noted, "Sometimes I did not understand the main text in the unit, so I often looked at the captions under the pictures as my source of SQG. The captions are short and easily comprehensible, so I hollowed out specific words or phrases to generate the questions" (interview).

As reflected, the causes of prohibiting average- and low-achievers from generating questions of higher cognitive levels vary from case to case and involve a variety of personal factors, including poor abilities in the subject matter and in the generation of multiple-choice questions, as well as overall reading comprehension.

In short, the difficulties with regard to SQG for theme 4 showed that the students, and especially the low- and average-achievers, failed to construct questions that involved higher-order cognitive levels.

\section{DISCUSSION}

The case study examined in this work revealed that the low-, average-, and high-achievers all encountered difficulties while engaging in SQG. Nevertheless, the difficulties they had faced varied, depending on a wide range of factors.

Firstly, a common difficulty students faced at the very beginning was their inability to find appropriate content and 
identify the main ideas in the study texts. This was particularly likely to occur with the low- and average-achievers, who tended to generate no questions, inappropriate questions or non-questions that did not address the main points of the study materials. For instance, Hsiao-hsin (A2), due to his absent-mindedness, and Te-wei (L1), due to his slow-learning ability, both could not direct themselves to find any appropriate content for SQG at the beginning of this project. Hsiao-chun (L2), on the other hand, was aware that she had a lot of choices, but she could not promptly determine the content of her SQG. This suggests that these students did not have good summarization or organization skills, which are essential for grasping the main ideas of the study material. Instructors are therefore recommended to help students extract the main ideas from a variety of sources, such as headings and subheadings in texts, topic sentences or summary sentences in text paragraphs, as well as keywords that are specially formatted or highlighted. These should provide some supportive scaffolds and directions for SQG.

Secondly, completing the specified number of questions with options of adequate quality was another difficulty that the students faced, as expressed. As Ta-han (H1) noted, he encountered difficulties in generating two questions, since certain units had fewer pages than others. The classroom observation data also showed that low-achievers, including De-wei (L1) and Hsiao-chun (L2), were not able to complete the SQG task which required them to generate two questions within the specified time. An alternative approach would thus be to apply SQG in a flexible and open-ended manner, in which the specified number of questions and the allotted time could be flexibly arranged to cope with the different learning needs and abilities of students [31]. On the other hand, it was found that students with different achievement levels also had difficulties in developing plausible options, with average- and low-achievers exhibiting great difficulties. Students of both average- and low-achievers appeared to overuse the options of all of the above and none of the above, respectively or simultaneously, especially when they could not come up with the needed options. To deal with the problem, as a possible method, instructors may direct the students to develop options from different units, rather than the current one.

Thirdly, it was found that the students had difficulties in formulating linguistically appropriate question stems. Two fundamental problems related to student-generated question stems are an awkward expression of the question form, and an extensive use of colloquial expressions. The prevalence of the former pointed to the fact that the students were not familiar with the standard writing conventions used for generic question stems, although the students used their mother tongue (i.e., Chinese) to construct their questions. The provision of generic question stems, as suggested by King [18], can enable students to generate questions with greater ease. On the other hand, the extensive use of colloquial language shows that the students, especially average- and low-achievers, failed to recognize the differences between written and spoken language when constructing question stems. Written language is formal and academic in style, and is made up of strict and appropriate words [32]. Extensively using colloquial language suggests that the students are not well aware of question stems as a particular genre of written language that requires more formal and elaborate expressions.

Fourthly, the last difficulty is concerned with students' inability to come up with questions that involve higher cognitive levels. The majority of questions produced by the average- and low-achievers were of the memory type, which suggests that these students predominantly applied lower thinking skills to generate questions while engaging in SQG. Nevertheless, the objective of studying social studies is not merely to memorize facts and details, as students are expected to develop such higher-order thinking as critical thinking, value judgment and problem-solving skills [33]. Progressively advancing the level of question-generation from a lower cognitive level to a higher one is thus a worthwhile direction to pursue. To this end, question models dealing with higher levels of cognitive complexity are suggested to be given to students so as to encourage them to go beyond more basic questions.

Moreover, the predominance of memory-type questions from average- and low-achievers compared to high-achievers may reveal individuals' different goal-setting behaviors in the context of SQG. Students who inappropriately saw the SQG as a task to be completed rather than one that would help their learning can be distinguished based on their adoption of two different types of personal goal orientations, namely, "performance-oriented goals" and "mastery-oriented goals" [34]." It is reasonably inferred that the average- and low-achievers were probably directed by the performance-oriented goals, since they appeared to generate a higher ratio of memory-type questions that are assumed to be completed with relative ease rather than questions associated with higher cognitive levels. For such students, generating memory-type questions not only immediately meets the teacher's requirement of completing the SQG task, but also avoids being judged as incompetent learners. In stark contrast, high-achievers, likely to be prompted by mastery-oriented goals, are prone to regard the SQG task as a means to master study materials, develop skills, and upgrade abilities. As a consequence, they are not restricted to generating memory-type questions and are more open to formulating higher-order ones for deeper learning. With this in mind, ways to help create classrooms with mastery-oriented goals so as to help transform individuals from performance- to mastery-oriented goals, thereby enhancing the cognitive growth of learners and meanwhile maximizing the learning effect of SQG, would be a worthwhile endeavor for practitioners.

In summary, of the four major types of difficulties identified by the researchers, low-achievers seemingly faced more problems than the average- and high-achievers in SQG. This merits additional attention on the part of low-achievers, since SQG in the present study was implemented under a free situation in which the students were given limited support to generate questions. As opposed to high-achievers, who are highly self-directed in nature, low-achievers are individuals with less self-regulation, less self-motivation, and less academic self-perceptions [35]. It may thus be a considerable challenge for low-achievers to independently engage in such 
self-initiated activities as SQG, and successfully construct the questions of adequate quality. To equip low-achievers with a good command of SQG, a moderate level of guidance, assistance, and supervision from either peers or from teachers is considered beneficial, and may be especially necessary at the induction stage. Utilizing a cooperative SQG technique or providing procedural prompts and scaffolds [20] from teachers are promising ways to mitigate low-achievers' difficulties in SQG, and help them keep up with the performance of their peers.

This study was conducted in social studies, a field that is a relatively underexplored area of research in SQG. It is thus interesting to draw a parallel comparison between the difficulties of SQG discovered in the present study and those reported in previous work. First, in terms of similarities, similar to the results found in terms of mathematical SQG in the accumulated literature [12], [24], it was found that the difficulties related to SQG in social studies are diverse, multiple, and interconnected with each other. Additionally, it was found that the causes of difficulties varied from person to person, and stem from a variety of sources, including the nature of the SQG activity itself, the characteristics of students, and the format of question generation, which reflects the fact that SQG enables learners to explore knowledge in a highly individualized way, and this thus leads to individual differences with regard to the perceived difficulties. On the other hand, in terms of discrepancies, past research reported that the greatest difficulty with the mathematical SQG is that students cannot understand the focal topic, concept, abstract ideas, or the given conditions [12]. More specifically, mathematical SQG requires students to demonstrate a certain level of prior knowledge in addition to the current study topic. As such, students who lack of some closely related mathematical knowledge may face difficulties in constructing questions on the current math topic. In contrast, this issue is less obvious in social studies, because the study materials are mainly made up of texts, and many times can stand on their own, rather than being a mixture of mathematical concepts and symbols. Regardless of their social studies academic performance in prior units, students can thus still manage to develop a basic comprehension of the current content for SQG, and thus may not encounter the severe level of difficulties that can be seen with mathematical SQG.

\section{CONCLUSION}

While the present study addressed the difficulties students encounter in SQG, it should not be mistaken as incorporating SQG into elementary social studies classrooms is infeasible and will bring about unsuccessful learning experiences for students. As a matter of fact, the students in this study benefited a lot, and became increasingly independent and self-reliant in learning through the SQG experience. The interviews revealed that students generally held a positive attitude towards SQG, and were more motivated to learn after engaging in it. Classroom observations also showed that the students became more intrigued to learn, more attentive in class, and acquired a stronger sense of achievement after their
SQG experience. It was further shown via document analysis that several questions generated by the students involved knowledge application of the study materials and addressed real-world issues, and some even involved knowledge integration across disciplines. These findings resonated with established literature that SQG is an effective pedagogy to transform students from passive receivers of information into active constructors of knowledge [1], [10]. Nevertheless, as was found in the present study, students did encounter a variety of difficulties while engaging in SQG. To maximize the benefits of SQG, it is suggested that customized pedagogical interventions and scaffolds in the form of procedural prompts (e.g., main ideas, generic question stems, story grammar category, and so on), modeled practice, checklists, and cue cards be applied to address the different needs of individuals engaged in SQG across a range of domains and disciplines, and at all levels of the education system [15]. The difficulties identified in the present study not only offer valuable information for differentiated scaffolds, but also leave a rich space for further exploration.

\section{REFERENCES}

[1] F. Y. Yu and Y. J. Chen, "Effects of student-generated questions as the source of online drill-and-practice activities on learning," British Journal of Educational Technology, vol. 45, pp. 316-329, 2014.

[2] F. Y. Yu and Y. H. Liu, "Creating a psychologically safe online space for a student-generated questions learning activity via different identity revelation modes," British Journal of Educational Technology, vol. 40, pp. 1109-1123, 2009.

[3] J. Devon, J. H. Paterson, D. C. Moffat, and J. McCrae, "Evaluation of student engagement with peer feedback based on student-generated MCQs," Innovation in Teaching and Learning in Information and Computer Sciences, vol. 11, pp. 27-37, 2012.

[4] J. Hardy, S. P. Bates, M. M. Casey, K. W. Galloway, R. K. Galloway, A. E. Kay et al., "Student-generated content: Enhancing learning through sharing multiple-choice questions," International Journal of Science Education, vol. 36, pp. 2180-2194, 2014.

[5] Y. F. Lan and P. C. Lin, "Evaluation and improvement of student's question-posing ability in a web-based learning environment," Australasian Journal of Educational Technology, vol. 27, 2011.

[6] H. McQueen, C. Shields, D. Finnegan, J. Higham, and M. Simmen, "Peerwise provides significant academic benefits to biological science students across diverse learning tasks, but with minimal instructor intervention," Biochemistry and Molecular Biology Education, vol. 42, pp. 371-381, 2014.

[7] H. Y. Sung, G. J. Hwang, and Y. C. Chang, "Development of a mobile learning system based on a collaborative problem-posing strategy," Interactive Learning Environments, vol. 24, pp. 456-471, 2016.

[8] H. C. Yeh and P. Y. Lai, "Implementing online question generation to foster reading comprehension," Australasian Journal of Educational Technology, vol. 28, pp. 1152-1175, 2012.

[9] F. Y. Yu, C. P. Wu, and C. C. Hung, "Are there any joint effects of online student question generation and cooperative learning?" The Asia-Pacific Education Researcher, vol. 23, pp. 367-378, 2014.

[10] F. Y. Yu, Y. H. Liu, and T. W. Chan, "A web-based learning system for question-posing and peer assessment," Innovations in Education and Teaching International, vol. 42, pp. 337-348, 2005.

[11] E. Stoyanova and N. F. Ellerton, "A framework for research into students' problem posing in school mathematics," Technology in Mathematics Education, pp. 518-525, 1996.

[12] H. Akay and N. Boz, "Prospective teachers' views about problem-posing activities," Procedia-Social and Behavioral Sciences, vol. 1, pp. 1192-1198, 2009.

[13] D. Chazan, "Where do student conjectures come from?" Empirical Exploration in Mathematics Classes, Craft Paper, pp. 95-8, 1995.

[14] E. A. Silver, "On mathematical problem posing," For the Learning of Mathematics, vol. 14, pp. 19-28, 1994.

[15] F. Y. Yu, "Scaffolding student-generated questions: Design and development of a customizable online learning system," Computers in Human Behavior, vol. 25, pp. 1129-1138, 2009. 
[16] S. Crespo and N. Sinclair, "What makes a problem mathematically interesting? Inviting prospective teachers to pose better problems," Journal of Mathematics Teacher Education, vol. 11, pp. 395-415, 2008.

[17] E. J. Short and E. B. Ryan, "Metacognitive differences between skilled and less skilled readers: Remediating deficits through story grammar and attribution training," Journal of Educational Psychology, vol. 76, pp. $225-235,1984$

[18] A. King, "Facilitating elaborative learning through guided student-generated questioning," Educational Psychologist, vol. 27, pp. 111-126, 1992

[19] S. I. Brown and M. I. Walter, The Art of Problem Posing, 3rd ed. Mahwah, N.J: Lawrence Erlbaum, 2005.

[20] F. Y. Yu and K. J. Pan, "The effects of student question-generation with online prompts on learning," Educational Technology \& Society, vol. 17, pp. 267-279, 2014.

[21] F. Y. Yu, H. C. Tsai, and H. L. Wu, "Effects of online procedural scaffolds and the timing of scaffolding provision on elementary Taiwanese students' question-generation in a science class," Australasian Journal of Educational Technology, vol. 29, pp. 416-433, 2013.

[22] K. C. Chuan, "Research study on sixth grade problem-posing instruction: Case of addition, subtraction and number comparison on decimals," M.S. thesis, Institute of Education, National Sun Yat-Sen University, Kaohsiung, Taiwan, 2006.

[23] M. L. Chuang, "The study of problem posing teaching activities in the seventh-grade math class," M.S. thesis, Institute of Education, National Sun Yat-Sen University, Kaohsiung, Taiwan, 2003.

[24] J. Cai, J. C. Moyer, N. Wang, S. Hwang, B. Nie, and T. Garber, "Mathematical problem posing as a measure of curricular effect on students' learning," Educational Studies in Mathematics, vol. 83, pp. 57-69, 2013.

[25] R. K. Yin, Case Study Research: Design and Methods, Los Angeles: Sage publications, 2014.

[26] S. J. Osterlind, Constructing Test Items: Multiple-choice, Constructed-Response, Performance, and Other Formats, Norwel MA: Kluwer Academic, 1998.

[27] M. B. Miles and A. M. Huberman, Qualitative Data Analysis: An Expanded Sourcebook, Thousand Oaks: Sage Publications, 1994.

[28] T. M. Haladyna, Developing and Validating Multiple-choice Test Items, 3rd ed. Mahwah, NJ: Lawrence Erlbaum Associates, 2004.

[29] N. E. Gronlund, Assessment of Student Achievement, 6th ed. Needham Heights, MA: Allyn \& Bacon, 1998.

[30] B. S. Bloom, Taxonomy of Educational Objectives: The Classification of Educational Goals, Handbook 1-2: Longmans: McKay, 1974

[31] F. Y. Yu and C. P. Wu, "The influence of perceived task value and difficulty of student question-generation on the use of learning strategies and achievement," Educational Review, pp. 183-216, 2014.
[32] N. C. Thanh, "The differences between spoken and written grammar in English, in comparison with Vietnamese," GIST Education and Learning Research Journal, vol. 11, pp. 138-153, 2015.

[33] Ministry of Education, The Grade 1-9 Curriculum Guidelines for Social Studies: Taipei, Taiwan: MOE, 2010.

[34] C. Ames, "Classrooms: Goals, structures, and student motivation," Journal of Educational Psychology, vol. 84, pp. 261-271, 1992.

[35] D. B. McCoach and D. Siegle, "A comparison of high achievers' and low achievers' attitudes, perceptions, and motivations," Academic Exchange, vol. 2, pp. 71-76, 2001.

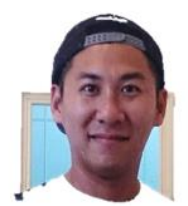

Chih-Wei Kuo received his master's degree in TESOL from National Chiao Tung University, Taiwan, in 2010. He is currently a Ph.D. student in the Institute of Education at National Cheng Kung University, Taiwan. His research interests include corpus-based content analysis, student-centered pedagogies, and computer-assisted language learning.

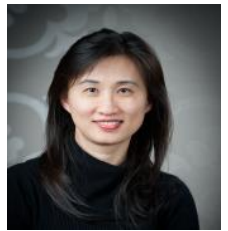

Fu-Yun Yu is a distinguished professor at the Institute of Education, National Cheng Kung University, Taiwan. She received her MA in educational systems development from Michigan State University in 1990, and $\mathrm{a} \mathrm{PhD}$ in instructional technology from the University of Texas at Austin in 1996. Her research interests include learner-centered strategies, adaptable learning space design, media effects, and technology-enhanced learning. For the past decade, her research has centered on strengthening the theoretical and empirical bases of student question-generation while exploring ways to integrate and scaffold the activity across multiple contexts and subjects.

She has published over 200 peer-reviewed publications that mostly pertain to ways of using emerging technology to increase learners' cognitive affective and social growth, the results of which have led to evidence-based suggestions and applications for practitioners and researchers. She has received several awards, including the Wu Ta-You Commemorative Award from the National Science Council in Taiwan (2004), the Outstanding Teacher of the Year from National Cheng Kung University (2006), the First Level Research Grant Award from the National Science Council in Taiwan (2005-2007, 2013-2014), and the Distinguished Researcher Award from the Asia-Pacific Society for Computers in Education (APSCE) (2009), among others. She served as the President of APSCE (2010/01-2011/12), Head of the Institute of Education and the Director of the Center of Teacher Education, National Cheng Kung University, Taiwan (2009/02-2012/01), and is a Fulbright senior research scholar hosted by the University of Chicago, USA (2012/03-2012/11) 